\title{
Livro didático de Física e de Ciências: contribuições das pesquisas para a transformação do ensino
}

\section{Physics and Science textbooks: research contributions to modification of teaching}

\author{
Nilson Marcos Dias Garcia ${ }^{1}$
}

\begin{abstract}
RESUMO
Este artigo sistematiza resultados de pesquisas sobre o livro didático de Física e de Ciências desenvolvidas no âmbito do Grupo de Estudos e Pesquisas em Ensino de Física da Universidade Tecnológica Federal do Paraná (UTFPR) e do Núcleo de Pesquisas em Publicações Didáticas da Universidade Federal do Paraná (UFPR). Evidencia a ausência de estudos didáticos e epistemológicos e avalia os resultados obtidos no âmbito de diferentes projetos, tanto no que se refere aos livros para alunos como no que diz respeito aos manuais para professores. Apresenta resultados indicativos para a ampliação da pesquisa nessa temática.
\end{abstract}

Palavras-chave: livro didático de Física; livro didático de Ciências; PNLD; PNLD-EM.

\begin{abstract}
This paper systematizes the results of research on Physics and Science textbooks developed by the Group of Studies and Research on Physics Teaching (UTFPR) and the Research Group on Didactical Publications (UFPR). It highlights the absence of didactic and epistemological studies on this subject and evaluates the results obtained in different projects, in regard to both students' books and teachers' manuals. The work presents results which indicate the need to expand research on this matter.
\end{abstract}

Keywords: Physics textbooks, Science textbooks, PNLD, PNLD-EM.

${ }^{1}$ Doutor em Educação. Universidade Tecnológica Federal do Paraná, Departamento Acadêmico de Física e Programa de Pós-Graduação em Tecnologia; Universidade Federal do Paraná, Programa de Pós-Graduação em Educação, Brasil. E-mail: nilson@utfpr.edu.br.

Com apoio parcial do CNPq. 


\section{Introdução}

O livro didático tem desempenhado, desde longa data, um importante papel no espaço escolar, constituindo-se, conforme Choppin (2004), em "suporte privilegiado dos conteúdos educativos, o depositário dos conhecimentos, técnicas ou habilidades que um grupo social acredita que seja necessário transmitir às novas gerações" (p. 553).

Pode-se dizer, concordando com Garcia (2011), que diversas dimensões da experiência escolar são afetadas pela presença dos livros nas salas de aulas: o ensino, os métodos, a avaliação, a imagem dos professores, o conhecimento, dentre outros. No entanto, do ponto de vista da pesquisa, pouco se conhece sobre esses temas. Por um lado, há uma forte tradição de estudar os livros; por outro, são pouco conhecidas as condições pelas quais eles afetam a vida escolar.

Nesse sentido, é razoável se pensar que a distribuição universalizada de livros didáticos para os alunos do Ensino Médio, ocorrida na última década, deve ter trazido para o interior das salas de aula uma série de situações que, por serem recentes, ainda necessitam ser estudadas, tendo em vista que na maior parte das escolas públicas, anteriormente, eram raras as situações em que os alunos possuíam livros didáticos.

No campo educacional brasileiro, portanto, essas investigações têm-se revelado de grande importância, tanto para analisar o efeito que a universalização dos livros pode provocar quanto para verificar os resultados do vultoso aporte de recursos financeiros envolvido na sua seleção, produção e distribuição. No caso particular da Física para o Ensino Médio, é preciso também analisar as mudanças que a presença dos livros nas salas de aula pode provocar, principalmente nos conteúdos e métodos de ensino. Praticamente cristalizado pela sua crônica ausência em salas de aulas e pelo uso intensivo do quadro de giz e registros em cadernos, o que acontecerá agora, com o modelo de ensino, quando o livro chega a todas as escolas? Eles afetarão os conteúdos e os métodos? As dinâmicas das aulas?

Esse é o tema privilegiado neste artigo. Primeiramente, serão apresentados alguns aspectos da história dos livros didáticos no Brasil, contextualizando a problemática. Em seguida, a questão será tratada tomando-se como referência as reformas educacionais brasileiras e o impacto que elas produziram sobre os livros didáticos, principalmente os de Física e de Ciências. Finalizando, serão analisadas pesquisas que tomam o livro como objeto de investigação e que buscam analisar os efeitos de sua presença nas salas de aula, de forma a apontar as potencialidades para novos estudos nesse tema. 


\section{Livros didáticos de Física e de Ciências no Brasil: sua historicidade}

A história do livro didático no Brasil, conforme Hallewell (2005, p. 237), pode ser registrada a partir de 1837, com a criação do Colégio D. Pedro II, no Rio de Janeiro. Nesse período, conforme apontado por Lorenz (2008), a maior parte dos livros utilizados no colégio era tradução de originais franceses, que, elaborados sob uma concepção humanista, acabaram por influenciar o modo de pensar a educação nacional. Essa influência francesa, que se manifestava também nos métodos de ensino e que permaneceu durante boa parte das primeiras décadas do século XX, deixou de ser predominante principalmente a partir da segunda metade daquele século, cedendo lugar à influência norte-americana.

No caso particular dos livros de conteúdos das Ciências Exatas, principalmente os de Física, Química, Biologia e Matemática, essa mudança ocorreu em grande parte devido ao significativo investimento no ensino dessas ciências nos Estados Unidos, decorrente da disputa pela predominância na corrida astronáutica entre este país e a então União Soviética e em decorrência da influência que os Estados Unidos exerciam sobre os países em desenvolvimento da América Latina.

Motivada pelo fato surpreendente do lançamento do satélite Sputnik em 1957 pelos soviéticos, houve uma aceleração nas reformas que estavam sendo promovidas no ensino norte-americano e, como consequência, uma mudança no enfoque do seu ensino secundário, retomando a "primazia dos conteúdos da matéria", em substituição ao "ensino das aplicações dos conceitos à vida quotidiana" (LORENZ, 2008, p. 9). Ao mesmo tempo, destinou-se um maciço apoio financeiro a diversos projetos educacionais em curso, principalmente no âmbito das Ciências da Natureza.

Não é o caso de aprofundar aqui essa questão, pois diversos autores apresentam e discutem com propriedade detalhes e implicações políticas e educacionais desse movimento para o Brasil, como, por exemplo, Romanelli (1986), Krasilchik (1987) e Lorenz (2008). Ressalte-se, entretanto, que alguns dos projetos de ensino de disciplinas científicas resultantes desse movimento, como, por exemplo, o Physical Science Study Committee (PSSC), o Biological Sciences Curriculum Study (BSCS), o Chemical Education Materials Study (CHEM Study) e o Chemical Bond Approach (CBA), influenciaram de maneira significativa a forma de ensiná-las em diversas partes do mundo e, no caso brasileiro em particular, provocaram uma inflexão no modelo de ensino, que passou a sofrer forte influência norte-americana, em substituição à influência europeia, principalmente nos materiais didáticos e livros (LORENZ, 2008). 
Cabe ressaltar, entretanto, que, decorrente de questionamentos sobre a eficácia e a adequação de manuais estrangeiros traduzidos para o português, começaram a ser desenvolvidos projetos nacionais para o ensino de Física, com o intuito de melhor atender as características da cultura das escolas e dos professores brasileiros. $\mathrm{Na}$ esteira do primeiro projeto nesse sentido - Projeto Piloto da UNESCO para o Ensino de Física (1964) -, destacam-se o Projeto de Ensino de Física (PEF), o Física Auto-Instrutivo (FAI) e o Projeto Brasileiro de Ensino de Física (PBEF), todos eles organizados por equipes de professores majoritariamente do Instituto de Física da Universidade de São Paulo.

Esses projetos, desenvolvidos em diversos momentos da década de 1970, desempenharam um papel significativo na constituição e na organização do campo de investigação em Ensino de Física, dado que, com o objetivo de produzir materiais mais adequados às condições e características das escolas brasileiras, pesquisadores e professores interessados na temática, predominantemente da Universidade de São Paulo, se articularam em torno deles, gerando condições ímpares de trabalho e pesquisa. Registre-se que em 1970 foi realizado o $1 .{ }^{\circ}$ Simpósio Nacional de Ensino de Física e as duas primeiras pós-graduações em Ensino de Física no Brasil, na USP e na UFRGS, são também criadas no começo dessa década.

No entanto, de forma semelhante ao que havia acontecido com os manuais norte-americanos traduzidos, esse conjunto de livros, embora bem estruturados e pautados nas concepções experimentais de ensino mais recentes, não obteve sucesso entre os professores brasileiros. Sua difusão e seu uso foram pouco significativos.

Em substituição aos manuais estrangeiros até então adotados, inclusive os elaborados no âmbito dos projetos, os livros didáticos produzidos no Brasil nas décadas de 1950 e 1960 que lograram resultados quanto à adoção pelas escolas e professores, com raras exceções, foram aqueles que buscavam atender aos programas dos exames vestibulares, conforme apontado por Wuo (2000):

[...] ainda que o exame [de sua pesquisa] não tenha sido focalizado nessa direção, alguns livros apontam para justificar a organização, orientações de comissões encarregadas da elaboração dos programas oficiais, portarias ministeriais, leis de diretrizes e bases etc. Nos livros das décadas de 50 e 60 encontram-se indicações explícitas sobre o atendimento às necessidades de preparação para os exames vestibulares, momento em que os livros sofreram transformação no sentido de abandonar uma forma mais descritiva dos produtos tecnológicos (física "prática") em favor de um tratamento quantitativo mais acurado (física "teórica"), o qual desempenhava um melhor papel ante os exames vestibulares. (p. 106). 
Essa tendência se manteria nos anos seguintes, conforme foi constatado pelo autor, ao analisar vinte e quatro livros didáticos de Física editados a partir de 1980. Wuo (2000) assim se manifesta a respeito de doze deles, dentre os quais alguns dos mais adotados pelos professores nas décadas de 1980 e 1990:

A maioria dessas obras não apresenta referências históricas, não relaciona a física com a vivência quotidiana, não traz aplicações tecnológicas, não aprofunda análises em casos particulares, nem aborda problemas mais elaborados. Quando refere-se a alguns desses pontos, fato ocasional, fá-lo de modo muito superficial, uma vez que o esquema geral dessas obras é a apresentação conceitual voltada à resolução de exercícios, mais para aplicação de fórmulas do que para outros aspectos e atividades integradoras com outras áreas e formas de raciocínios. Daí trazerem um número sempre elevado de exercícios propostos e modelos resolvidos, com ausência completa de problemas mais abrangentes. Muitos desses livros assemelham-se às apostilas dos cursinhos pré-vestibulares da década de 70, um pouco mais elaborados, é claro. (p. 53)

Os aspectos indicados pela análise de Wuo (2000) são coerentes com a expectativa de alunos e professores em relação ao então denominado Ensino de $2{ }^{\circ}$ Grau. Apesar de estar sendo regido por uma legislação que preconizava, dentre suas finalidades, que aquele nível de ensino deveria estar em "consonância com as necessidades do mercado de trabalho local ou regional" (art. 5. ${ }^{\circ} \mathrm{da}$ lei 5.692/1971), na prática os alunos visavam à continuidade dos estudos em nível superior, cujo acesso acontecia por um processo de seleção - o vestibular - que, no caso da Física, valorizava sobremaneira a habilidade em interpretar e resolver problemas numéricos.

Essa tendência passaria a ser revista, principalmente a partir da década de 1990, em função das mudanças ocorridas na organização social mundial e nacional, atribuídas à globalização e à velocidade de circulação de informações, que colocaram em evidência outras necessidades e expectativas para a educação, fazendo com que a escola assumisse a responsabilidade de abordar novos conhecimentos em consonância com as mudanças ocorridas nos "grandes centros" (EUA e Europa).

Dessa forma, quase ao final do século XX, a legislação de ensino no Brasil foi reestruturada, apontando novos objetivos para a educação nacional e ampliando os fins do Ensino Médio, atribuindo-lhe como finalidades, dentre outros aspectos, tanto a possibilidade de continuidade de estudos como a preparação básica dos alunos para o trabalho e a cidadania. Conforme especificado na 
legislação, "para continuar aprendendo, de modo a ser capaz de se adaptar com flexibilidade a novas condições de ocupação ou aperfeiçoamento posteriores", assim como para "a compreensão dos fundamentos científico-tecnológicos dos processos produtivos, relacionando a teoria com a prática, no ensino de cada disciplina." (BRASIL, 1996, art. 5. ${ }^{\circ}$ ).

Essas novas finalidades se traduziram em um conjunto de ações políticas que implicaram orientações e recomendações consubstanciadas nas Diretrizes Curriculares Nacionais para o Ensino Médio (DCNEM), nos Parâmetros Curriculares Nacionais para o Ensino Médio (PCNEM) e nas Orientações Educacionais Complementares aos Parâmetros Curriculares Nacionais (PCN+ Ensino Médio), que serviram de referência para a organização de diversos programas e ações, dentre os quais aqueles relacionados aos livros didáticos.

\section{As orientações curriculares nacionais e a produção dos livros didáticos de Física}

Elaborada num contexto livre das restrições impostas pelo período de ditadura militar (1964-1985) que a antecedeu, a nova legislação de educação, Lei 9.394, de 1996, mesmo não correspondendo ao projeto que fora construído com a participação intensa da sociedade civil organizada, procurou incorporar demandas da contemporaneidade para a formação das crianças e jovens brasileiros.

À sua aprovação seguiu-se a produção de diversos instrumentos legais para sustentar sua implementação, dentre os quais as DCNEM e os PCNEM. Assim, tanto as Diretrizes como os Parâmetros, ao estabelecerem objetivos e finalidades para a educação, também indicaram os elementos que passariam a ser determinantes na organização escolar, inclusive no que diz respeito aos livros didáticos.

A esse respeito, destaca-se que o Brasil tem, hoje, um programa - sem equivalentes - de avaliação, aquisição e distribuição de livros didáticos para todos os alunos da Educação Básica, cuja avaliação é orientada por critérios editoriais, pedagógicos e didáticos específicos, desenvolvendo, desde 1938, ações nesse sentido, fato que já tem sido tratado com propriedade por diversos autores, como, por exemplo, Höfling (2006), Leão e Megid Neto (2006), Amaral (2006), Megid Neto e Fracalanza (2006), dentre outros.

Entretanto, para os jovens do Ensino Médio, o acesso aos livros só se efetuou recentemente, com a ampliação do Plano Nacional do Livro Didático e a criação do Programa Nacional do Livro Didático para o Ensino Médio PNLEM, por meio da Resolução FNDE n. ${ }^{\circ}$ 38/03 (BRASIL, 2003). Na última 
década, portanto, começaram a ser construídas as condições para que os alunos do Ensino Médio das escolas públicas também passassem a receber livros didáticos gratuitamente, o que aconteceu com os de Física, pela primeira vez, em 2009, rompendo, assim, a crônica falta do livro didático dessa disciplina nas mãos dos alunos e professores.

Essa questão deve ser enfatizada, uma vez que a ausência de livros na maioria das escolas públicas do Ensino Médio contribuiu para a constituição de determinados modelos de aula de Física, entre os quais aquele baseado na escrita dos textos, fórmulas ou sínteses no quadro de giz, com a cópia dos alunos feita em seus cadernos. A leitura, nesse modelo, tem pouco espaço, assim como outras estratégias para ensinar e aprender.

Portanto, entende-se que a presença universalizada dos livros de Física na escola, assim como apontado por Silva, Garcia e Garcia (2010), pode significar também uma possibilidade de ruptura com os modelos hegemônicos que estão hoje presentes nas escolas públicas do país.

Apoiado na experiência acumulada com a avaliação que já vinha sendo realizada nos livros do Ensino Fundamental, o PNLEM incluiu, desde o seu início, mecanismos de avaliação dos livros submetidos ao Programa de tal forma que só seriam encaminhados à escolha dos professores aqueles que houvessem sido aprovados inicialmente por uma equipe avaliadora, cujos critérios deveriam se apoiar nas concepções presentes na legislação educacional, respeitando principalmente as DCNEM e os PCNEM.

Em função disso, e consoante as novas expectativas para o Ensino Médio, as orientações tomadas como referência para a seleção dos livros didáticos de Física levam em conta que o "novo" Ensino Médio, de acordo com Mello (2005, p. 1), deve apresentar uma "reorganização curricular baseada na contextualização, nas tecnologias e na interdisciplinaridade." e um "ensino mais geral, inovador e menos conteudista". Nessa abordagem, perdem força, portanto, as propostas que enfatizam a pura memorização, os cálculos repetitivos, os exercícios descontextualizados.

Evidenciando a articulação entre as diversas ações propostas, essas orientações são também aplicadas ao Exame Nacional de Ensino Médio (ENEM), que passa a ser um forte indutor da organização curricular do Ensino Médio. Compartilhando o espaço antes ocupado hegemonicamente pelo vestibular, outros parâmetros são estabelecidos, tanto para a organização curricular como para a elaboração dos livros didáticos das diversas disciplinas do Ensino Médio.

Dessa forma, o conteúdo dos editais que norteiam a seleção dos livros didáticos para o Ensino Médio induz algumas alterações em sua produção, que, no caso particular da Física, podem ser analisadas sob algumas perspectivas: dos autores, das editoras, da organização de conteúdos e da escolha pelos professores. 
Tomando como referência os dados apresentados por Wuo (2000, p. 44 e 45), que se apoiou na declaração de professores do Ensino Médio para compor uma relação de autores usualmente adotados entre 1980 e final dos anos 1990 (antes do PNLEM, portanto), percebe-se que houve uma significativa mudança nesse particular após o PNLEM. Poucos são os autores de livros anteriormente adotados cujos textos foram aprovados nessa nova forma de avaliação, tanto na primeira, ocorrida em 2007, quanto na segunda, em 2011. Permaneceram basicamente os que já apresentavam uma proposta diferenciada ou aqueles que conseguiram se adaptar às novas exigências.

Sob a ótica das editoras, entretanto, pouca mudança ocorreu. Quase toda a produção de livros didáticos de Física ficou praticamente sob a responsabilidade do mesmo grupo reduzido de editoras, tanto antes quanto depois do PNLEM, o que, segundo Höfling (2006, p. 31), faz com que elas possam ser consideradas "como "parceiras" constantes do MEC na programação do PNLD.". Deve-se relembrar, aqui, que os livros são produtos do mercado, como analisado por Apple (1995); o volume de recursos públicos investidos na aquisição de livros escolares no Brasil é bastante significativo e, como se tem apontado, constitui-se em um dos fatores mais fortes de sustentação econômica e lucro das editoras brasileiras.

Por outro lado, quanto à organização dos conteúdos, merece especial atenção a análise que Mello $(2005$, p. 2) faz da questão, ao relacionar as DCNEM, os PCNEM, o PNLEM e a materialização dessas orientações nos livros didáticos. Pondera a autora que

[...] os livros didáticos da área de Ciências da Natureza, Matemática e suas Tecnologias se apropriam da ideia de mudança da reforma, através da incorporação dos princípios preconizados, porém sem mudarem significativamente os critérios de seleção e organização dos conteúdos. Os livros didáticos se apropriaram dessa ideia, antes mesmo dos conceitos das disciplinas que vinculam, para poderem mudar e, ao mesmo tempo, não mudar. Ou seja, o mundo editorial produziu mudanças significativas na confecção dos livros, às vezes incorporando ideias particulares já existentes em alguns grupos disciplinares, antes mesmo da elaboração dos PCNEM. Por outro lado, os livros didáticos continuam a apresentar uma estrutura e organização linear em unidades, capítulos e conteúdos, conforme encontramos em livros anteriores à reforma.

A análise dos livros didáticos no último PNLD-EM (2011) indica que, do ponto de vista dos avaliadores, em apenas duas das dez coleções aprovadas a 
apresentação dos conteúdos ocorre de forma tradicional, corroborando a ideia apresentada pela autora de que as mudanças, efetivamente, não mudaram muita coisa.

Finalmente, trazendo à tona como tais coleções têm sido vistas pelos professores e analisando as estatísticas das compras efetuadas, pode-se perceber que aquelas avaliadas como propostas tradicionais foram as que tiveram maior adesão por parte dos professores. Por outro lado, as duas coleções consideradas mais inovadoras ficaram na 7. ${ }^{\mathrm{a}} \mathrm{e} 9 .^{\mathrm{a}}$ colocações na escolha dos professores.

Essas questões demonstram que muito ainda terá que ser investigado e experimentado para que se encontrem parâmetros que deem conta de equacionar os complexos problemas envolvidos na produção e na distribuição de livros didáticos, esse importante artefato da cultura escolar que desempenha um significativo papel na vida escolar, tanto na constituição do conhecimento a ser ensinado e aprendido, como nas formas pelas quais as aulas são organizadas.

Além disso, e sem deixar de relevar essas questões e a importância da qual tem se revestido o PNLD-EM por democratizar o acesso dos professores e estudantes aos livros didáticos, um aspecto que tem sido pouco abordado no âmbito do PNLD-EM diz respeito ao uso que os professores e alunos têm feito dos livros que passaram a receber.

O Programa tem cumprido a função de fazer chegar os livros à escola. No entanto, sua presença nas aulas abre espaço para a pesquisa educacional e, em especial, para a pesquisa em ensino, na direção de estudar e compreender o que acontece no âmbito escolar com o uso dos livros. O investimento nessa questão é apontado como uma necessidade por diferentes pesquisadores do tema (CHOPPIN, 2004, por exemplo) e também pelo Núcleo de Pesquisa e Produção Didática (NPPD) da UFPR, assim como pelo Grupo de Estudos e Pesquisas em Ensino de Física (GEPEF) da UTFPR, cujas pesquisas serão analisadas a seguir.

\section{Analisando o resultado de pesquisas sobre o livro didático de Física e de Ciências}

Dadas as transformações que os livros sofrem e admitindo-se que eles expressam elementos da cultura escolar, tomar esse artefato como objeto de análise continua a ser necessário e relevante para a pesquisa em educação e em ensino. Por outro lado, considerando-se que eles são inseridos nas escolas e nas aulas de diferentes formas e dinâmicas e entendendo-se que também são diversos os processos de sua incorporação e apropriação pelos professores e 
alunos, é preciso investigar os livros na vida escolar. Revelam-se, assim, duas abordagens nas investigações: aquelas que tomam o livro como objeto e aquelas que estudam a sua presença nas escolas.

Quanto aos livros de Ciências para o Ensino Fundamental, cuja distribuição aos alunos por meio do PNLD já ocorre há mais de três décadas, pode-se falar em uma tradição na pesquisa com a primeira abordagem. Conteúdos dos livros e equívocos conceituais, por exemplo, são temas recorrentes em publicações científicas. Porém, são ainda escassos os estudos sobre os livros nas aulas.

No que se refere à especificidade dos livros de Física, deve-se lembrar que apenas nos últimos cinco anos eles passaram a ser avaliados dentro do Programa Nacional e somente há três são distribuídos aos alunos das escolas públicas. Portanto, estudos anteriores a esse período dizem respeito aos livros utilizados essencialmente pelas escolas privadas e, nesse sentido, pode-se falar em uma preocupação reduzida dos pesquisadores do tema e ressaltar que a presença dos livros de Física nas escolas públicas é carente e estimuladora de novas pesquisas.

Por outro lado, em decorrência de reformas educativas, das novas finalidades do Ensino Médio e também dos resultados de investigações no campo de Ensino de Física, eles têm incorporado, em maior ou menor intensidade, diferentes e novos conteúdos e novas formas de trabalhar os conhecimentos físicos. Assim, os estudos que tomam o livro como objeto de análise têm se desenvolvido para compreender o grau das transformações ocorridas, dentro dos novos parâmetros.

Dessa forma, tanto no caso das Ciências como no da Física, defende-se a necessidade e a relevância de pesquisas sobre a temática dos livros didáticos, nas duas abordagens indicadas.

Neste artigo serão consideradas algumas das pesquisas desenvolvidas por professores e por alunos como estudos de Iniciação Científica, de Mestrado e Doutorado. Elas têm sido realizadas no âmbito da Linha de Pesquisa Cultura, Escola e Ensino do Programa de Pós-Graduação em Educação da Universidade Federal do Paraná, com a participação de pesquisadores do Núcleo de Pesquisa e Publicações Didáticas (NPPD-UFPR), e do Grupo de Estudos e Pesquisas em Ensino de Física (GEPEF-UTFPR) e tomaram como objeto científico múltiplos aspectos do livro didático de Física e de Ciências, evidenciando o interesse e a atualidade dessa temática. 


\section{O livro didático de Física e de Ciências como objeto de investigação}

O primeiro trabalho desenvolvido no âmbito desses grupos intitula-se $A$ história da indução eletromagnética contada nos livros didáticos de Física, dissertação de Cristiano Carvalho ${ }^{2}$, defendida em 2007. Abordando aspectos da História da Ciência e de sua contribuição para o ensino de Física, a opção por estudar os livros didáticos foi feita, conforme explicitado por Carvalho, "devido à sua marcante presença como importante elemento de registro das formas de ensino em determinados períodos.”.

O material empírico constituiu-se dos livros didáticos de Física aprovados no PNLEM 2007. Os dados foram analisados segundo quatro categorias: a) interação, que visa analisar, no livro, como é explicado o desenvolvimento de uma teoria, se através de trabalho individual ou coletivo; b) atores, que analisa se são apresentados apenas os cientistas mais consagrados ou se é feita menção a outras pessoas que colaboraram com o desenvolvimento das teorias; c) métodos, que analisa como o autor explica o processo de criação e desenvolvimento de uma teoria, se valoriza mais o aspecto experimental ou o teórico; e d) construção da ciência, que procura identificar como é apresentada a construção da ciência, se feita apenas de acertos ou de acertos e erros, se de maneira cumulativa ou através de rupturas.

Concluiu-se que nos livros didáticos analisados, tomando como caso particular a história da indução eletromagnética, excepcionalmente a construção da ciência é apresentada como um processo, com participação de diversos atores, cotejada por erros e acertos. Prevaleceu a concepção de que o processo de criação é individual, realizado por pessoas geniais que se valem, preferencialmente, da experimentação e da observação, sendo apresentados apenas os resultados positivos das tentativas da construção do conhecimento.

Uma investigação que tomou os livros como objeto, denominada Características dos textos introdutórios para ensino de dinâmica em livros didáticos, foi desenvolvida pelo aluno Luiz Gustavo $\mathrm{Pampu}^{3}$ como trabalho de introdução à pesquisa no Curso de Licenciatura em Física. Na sua justificativa, o autor ressalta a importância de que se reveste a apresentação de um tema ou capítulo,

\footnotetext{
${ }^{2}$ Disponível em: $<$ http://hdl.handle.net/1884/11761>.

${ }^{3}$ Texto completo de trabalho apresentado no IX Congresso Nacional de Educação - EDUCERE, disponível em: <http://www.pucpr.br/eventos/educere/educere2009/anais/pdf/3371_1710. pdf $>$.
} 
considerando-se as indicações, no campo da Didática da Física, de que a introdução dos temas e assuntos seja feita a partir de uma problematização. Assim, propôs-se a analisar os textos introdutórios de Dinâmica, interpretando como se posicionam, nesse particular, os autores dos livros analisados.

Foram analisados três livros didáticos de Física aprovados no Programa Nacional do Livro Didático de Ensino Médio (2009). Os resultados permitiram indicar que os textos introdutórios apresentam "caráter descritivo, deixando pouco espaço à produção de significados pelo leitor e, ainda, com pouco estímulo à problematização e análise de situações." Sob o ponto de vista pedagógico, os textos foram considerados diretivos, contribuindo "para a propagação de mitos referentes à ciência e tecnologia". Constatou-se "a ausência de uma articulação entre metodologia e conteúdo", não conseguindo atender satisfatoriamente as propostas metodológicas das diretrizes governamentais e dos autores do campo da Didática da Física.

A dissertação de Marcus Vinicius Urbinatti Canhete, intitulada Os PCNs $e$ as inovações didáticas nos livros de Ciências ${ }^{4}$, por sua vez, investigou se e como as inovações no ensino recomendadas nos PCNs de Ciências estão sendo incorporadas nos livros didáticos de Ciências. Tendo em vista a importância assumida pelos livros didáticos nas salas de aula e a avaliação do Programa Nacional do Livro Didático, que respeita as orientações emanadas dos PCNs, foram tomados como objeto de investigação os livros didáticos de Ciências dos últimos anos do Ensino Fundamental indicados pelo PNLD 2011.

Tomando como caso particular as temáticas relativas ao enfoque Ciência, Tecnologia e Sociedade (CTS) e da História e Filosofia da Ciência (HFC) e apoiando-se metodologicamente nos pressupostos da Análise de Conteúdo, "foram estabelecidas categorias de avaliação aplicáveis às temáticas Poluição e Astronomia, indicativas respectivamente da presença do enfoque CTS e HFC, em três das coleções aprovadas pelo PNLD 2011".

Os resultados obtidos indicaram que o Guia PNLD, material disponibilizado aos professores com os resultados da avaliação, para que usem ao fazer a sua escolha, "não oferece informações suficientemente claras para avaliar a presença das inovações nos livros de Ciências". No entanto, a análise realizada nos livros aprovados mostra que já incluem algumas delas, embora "de forma insuficiente para promover uma transformação no ensino de Ciências".

Deve-se ressaltar que ao longo das últimas três décadas foram produzidas transformações nos livros didáticos, em grande parte por efeito do PNLD. Títulos foram incluídos e excluídos do Programa e, assim, também deixaram

${ }^{4}$ Disponível em: <http://dspace.c3sl.ufpr.br/dspace/handle/1884/26864>. 
de ser editados muitos livros que eram considerados como bem aceitos entre os professores das redes pública e privada de ensino.

No caso da Física, particularmente se destaca uma obra que tem sido reeditada há mais de trinta anos com grande aceitação entre os docentes, principalmente das escolas da rede particular, demonstrando longa permanência na cultura escolar. Em 2007, passou a constar do catálogo do PNLEM e, portanto, tornou-se acessível às escolas públicas. No último processo de escolha do PNLD-EM, ficou em $6 .^{\circ}$ lugar na preferência dos professores, atingindo a marca aproximada de 900.000 livros solicitados para as três séries do Ensino Médio.

A obra em questão, de Antonio Máximo Ribeiro da Luz e Beatriz Álvares Alvarenga, tem sido objeto de estudo por Garcia e Trebien (2011-2012) e para sua análise, como primeira etapa da pesquisa, foi organizado um instrumento que permitisse captar suas especificidades e compreender razões do seu sucesso entre os professores de Física. A elaboração do instrumento foi apoiada em pressupostos e resultados de pesquisas sobre ensino de Física e poderá, também, auxiliar o trabalho dos professores na avaliação dos livros didáticos selecionados pelo PNLD-EM. ${ }^{5}$

Dessa forma, para além da análise de uma obra específica, a pesquisa pretende contribuir para suprir uma lacuna constatada na formação de professores quanto aos debates e propostas para avaliação de livros didáticos.

Nas pesquisas anteriormente relatadas, tem-se buscado inserir a discussão sobre os livros didáticos de Ciências e de Física em um campo teórico que permita explicar elementos do livro na sua relação com outros do campo da Didática, como, por exemplo, as prescrições curriculares e as contribuições produzidas no âmbito da pesquisa em ensino.

Trabalha-se, portanto, a partir da sugestão dada por Choppin (2004) no sentido de ampliar o espectro de estudo, com a perspectiva de desenvolver pesquisas com foco didático e epistemológico. Os livros usados pelos alunos, nessa direção, são examinados em sua estrutura e organização externa, no diálogo com outros elementos da cultura escolar.

Ao lado das pesquisas sobre os livros destinados aos alunos, um outro conjunto de estudos se concentra sobre os manuais destinados aos professores. Trata-se de um projeto denominado Ensinar a Ensinar: manuais destinados à formação de professores no Brasil. ${ }^{6}$ No âmbito desse projeto, Garcia e Esthenes

\footnotetext{
${ }^{5}$ Texto de trabalho apresentado no VIII Encontro Nacional de Pesquisa em Educação em Ciências - VIII ENPEC, disponível em: <http://www.nutes.ufrj.br/abrapec/enpecatual.html $>$.

${ }^{6}$ Projeto coordenado pela Profa. Dra. Tânia Maria F. Braga Garcia, no Núcleo de Pesquisa e Produção Didática, da UFPR (http://www.nppd.ufpr.br).
} 
do Nascimento ${ }^{7}$ catalogaram manuais didáticos destinados a orientar professores para ensinar Ciências e Física.

Os estudos sobre os manuais se revestem de grande importância, pois, "concebidos como materiais que poderiam contribuir para a formação dos professores, ensinando-lhes a ensinar", também "possibilitam análises relacionadas às concepções de ensino e aprendizagem, aos princípios didáticos gerais, aos conteúdos de ensino e às metodologias, particularmente neste caso quanto ao que significa ensinar e aprender Ciências e Física em dados momentos históricos, no país."

Mudanças e permanências puderam ser localizadas, como, por exemplo, a valorização de atividades realizadas pelos alunos para aprender Física, encontrada em um manual de 1930, de Toledo, que permanece ao longo do século e ainda circula nas orientações dadas aos professores, enfaticamente apoiadas nas contribuições da Psicologia.

Foram localizados, segundo a pesquisa, manuais de três tipos: aqueles que num contexto de Didática Geral abordam noções de didáticas específicas, dentre elas as de Física e de Ciências; aqueles de Didática da Física e aqueles de Didática das Ciências, abrangendo um período que vai de 1930 até 2007.

As análises apresentadas mostram a potencialidade de estudos que tomam os livros para professores como objeto de investigação, seja para compreender as transformações que as orientações sofrem ao longo dos anos, seja para verificar a permanência de formas de compreender o ensino de Ciências e Física, seus objetivos, métodos e recursos.

\section{A presença dos livros didáticos de Física e Ciências nas escolas}

Vários trabalhos também foram desenvolvidos analisando a presença dos livros nas salas de aula. $\mathrm{O}$ primeiro deles, intitulado $O$ uso do livro didático de Física: estudo sobre a relação dos professores com as orientações metodológicas $^{8}$, foi desenvolvido durante o período de iniciação científica do aluno Luiz Eduardo Pivovar.

Ressaltando que têm sido poucos os trabalhos que abordam o uso que os professores fazem do livro didático em geral e de Física em particular, da pes-

\footnotetext{
${ }^{7}$ Texto completo de trabalho apresentado no IX Congresso Nacional de Educação - Educere, disponível em: <www.pucpr.br/eventos/educere/educere2009/anais/pdf/3627 2037.pdf>.

${ }^{8}$ Texto completo de trabalho apresentado no VI Encontro Nacional de Pesquisa em Educação em Ciências, disponível em: <http://www.nutes.ufrj.br/abrapec/vienpec $>$.
} 
quisa participaram sete professores que responderam a um instrumento, que continha questões fechadas e abertas, e concederam uma entrevista ao pesquisador. Além disso, houve observação das aulas dos professores e análise documental.

Visando identificar as relações que os professores estabelecem com o livro didático de Física, a pesquisa procurou: “a) analisar as formas pelas quais os professores se apropriam dos manuais didáticos para a produção de suas aulas; b) explicar as formas que o conhecimento escolar assume a partir da produção de conhecimento feita pelos professores em suas aulas, utilizando o manual escolar; c) compreender o significado atribuído pelos professores às orientações didático-metodológicas apresentadas pelos autores no livro didático."

Resultados apontaram que, entre os colaboradores, poucos tiveram contato com livros durante sua graduação, ressaltando o estudo por meio de cadernos e apostilas, aspecto que provavelmente deve servir de modelo para sua atuação em sala de aula. A maior parte deles relata que, quando utiliza o livro, o usa para o planejamento das aulas, busca de referências, exercícios e experimentos para o trabalho com os alunos. Para as atividades em sala de aula, usa textos fotocopiados ou as anotações em cadernos. Com relação às orientações metodológicas presentes nos livros, ao mesmo tempo em que relatam que as leem, indicam que elas estabelecem pouca relação com a realidade das escolas.

A pesquisa também destacou existirem indícios da relação que pode ser estabelecida entre a formação dos professores e seu interesse pelas orientações: quanto maior o nível de formação, maior interesse em ler e discutir as orientações apresentadas pelos autores do livro.

Tendo como foco o livro didático de Ciências, a dissertação de Denise Estorilho Baganha, intitulada O papel e o uso do livro didático de ciências nos anos finais do ensino fundamental 9 , defendida em 2010, "apresenta os resultados de uma investigação sobre como os professores de Ciências dos anos finais do Ensino Fundamental utilizam o livro didático de Ciências e o papel desse recurso no planejamento e execução das suas aulas", especialmente quanto aos conteúdos de Física.

Realizada como pesquisa qualitativa, foram realizadas entrevistas com professoras de Ciências dos últimos anos do Ensino Fundamental atuantes em Curitiba e sua Região Metropolitana. Os resultados indicaram que as professoras, de acordo com as suas concepções pedagógicas, selecionam os conteúdos do livro didático e os utilizam "como organizador[es] do currículo escolar", “adequando-os à realidade onde trabalham”. Verificou-se também que o livro tem assumido um papel de material de apoio, "compartilhando espaço com TV, DVD, Vídeos, internet e computadores", deixando de ser única fonte de informação.

\footnotetext{
${ }^{9}$ Disponível em: <dspace.c3sl.ufpr.br/dspace/handle/1884/26239>.
} 
Com relação a trabalhar em sala de aula com os conteúdos de Física, a maioria das professoras declarou sentir dificuldades, "devido à formação inicial carente e pela falta de afinidade com a área". Nesse particular, na visão das professoras entrevistadas, o livro didático acaba não contribuindo "para o desenvolvimento dos conteúdos, tendo em vista que ainda apresentam maior ênfase nos cálculos, pouca interdisciplinaridade e contextualização", diferindo das propostas apresentadas nas orientações estadual e nacional.

Intitulada Os livros didáticos de Física do Ensino Médio: com a palavra os alunos, a dissertação de Eder Francisco da Silva ${ }^{10}$, apresentada em 2012, teve por objetivo analisar, a partir de investigação com alunos do Ensino Médio e também com recém-ingressantes no Curso de graduação em Física, o papel e o significado dos livros didáticos de Física que utilizaram durante o Ensino Médio. Realizada sob os pressupostos de pesquisa qualitativa, os participantes, entendidos como sujeitos sociais e históricos, responderam questionários sobre elementos de sua experiência com os livros didáticos de Física durante o ensino médio.

As análises dos dados foram feitas no sentido de explicitar "como os livros didáticos afetam a experiência escolar e os significados a eles atribuídos na sua relação com a aprendizagem da Física.". Os resultados também indicaram haver uma "predominância de práticas de utilização do quadro de giz", em detrimento do uso dos livros didáticos no desenvolvimento das aulas. Apontaram que, apesar da presença dos livros nas escolas, eles são pouco utilizados e, quando o são, prevalece o uso por causa de exercícios, esquemas e desenhos.

Os alunos também "destacaram a importância do professor na mediação entre o livro didático, o aluno e o conhecimento" e reconheceram que "a presença dos livros didáticos de Física pode auxiliar o professor em suas atividades" e "contribuir para a aprendizagem".

\section{Considerações finais}

As reformas educacionais que ocorreram com e após a LDB 9.394/96 implicaram novas diretrizes e parâmetros para a educação nacional que, organicamente, estabeleceram novas exigências para autores e editoras de livros didáticos, gerando um fértil campo para investigações em que o livro didático seja tomado como objeto e também para aquelas que pesquisem os efeitos que

${ }^{10}$ Sob orientação dos Profs. Dr. Nilson Marcos Dias Garcia e Dra. Tânia Maria F. Braga Garcia. 
a sua presença poderia causar nas salas de aulas, tanto do Ensino Fundamental quanto do Ensino Médio.

Integrantes do Núcleo de Pesquisas em Publicações Didáticas e do Grupo de Estudos e Pesquisas em Ensino de Física têm conduzido estudos com essa finalidade, que deverão ser ampliados e aprofundados. Como resultados indicativos dessas investigações, pode-se dizer:

- os livros didáticos de Ciências e de Física têm sofrido mudanças, mas os Guias do Livro Didático (PNLD) oferecem aos professores livros que incorporam as orientações oficiais de diferentes formas e em diversos graus. Tendo em conta que apenas dois dos títulos aprovados em Física foram considerados inovadores, isto é, atenderam às orientações curriculares nacionais para o ensino de Física, essa temática deverá ser investigada para acompanhar os processos de escolha e uso, compreendendo como os professores se relacionam com materiais mais convencionais ou mais inovadores;

- a formação inicial e continuada de professores, de forma geral, abre pouco (ou nenhum) espaço ao debate com os livros didáticos e seus usos, bem como sobre critérios de avaliação desses materiais;

- o interesse dos professores pelo livro, diferentemente do que circula na cultura escolar e mesmo em publicações sobre o tema, parece ser diretamente proporcional ao grau de formação que possuem, o que reforça a necessidade de uma formação mais consistente e densa.

Com esses resultados, conclui-se enfatizando a relevância de ampliar os estudos sobre os livros, incorporando contribuições da Didática Específica em Ciências e Física. Aponta-se também a necessidade de que as políticas e práticas de formação de professores contemplem propostas formadoras que incluam a discussão de temas relevantes como o livro didático, entre outros recursos que hoje estão sendo disponibilizados, inclusive de forma gratuita, aos alunos das escolas públicas brasileiras.

Em particular, os avanços no campo da pesquisa em Ensino de Física e de Ciências sugerem a produção e a utilização de livros em outros patamares. É necessário, portanto, investigar como essas novas abordagens poderão afetar as formas de ensinar e aprender Física e Ciências.

\section{Agradecimentos}

Agradeço à Dra. Tânia Maria F. Braga Garcia pela leitura crítica e sugestões. 


\section{REFERENCIAS}

AMARAL, I. A. Os fundamentos do ensino de Ciências e o livro didático. In: FRACAlANZA, H.; MEGID NETO, J. (Orgs.). O livro didático de Ciências no Brasil. Campinas: Komedi, 2006.

APPLE, Michael W. Trabalho docente e textos: economia política das relações de classe e de gênero em educação. Trad. Thomaz Tadeu da Silva, Tina Amado e Vera Maria Moreira. Porto Alegre: Artes Médicas, 1995.

BRASIL. Lei n. 5.692, de 11 de agosto de 1971. Fixa diretrizes e bases para o ensino de 1. ${ }^{\circ}$ e 2. ${ }^{\circ}$ graus, e dá outras providências. Brasília: Congresso Nacional, 1971.

. Lei n. 9.394, de 20 de dezembro de 1996. Estabelece as diretrizes e bases da Educação Nacional. Brasília: Congresso Nacional, 1996.

. FNDE. Resolução FNDE n. 38, de 15 de outubro de 2003. Brasília: Ministério da Educação, 2003.

CHOPPIN, Alain. História dos livros e das edições didáticas: sobre o estado da arte. Educação e Pesquisa, São Paulo, v. 30, n. 3, p. 549-566, set./dez. 2004.

GARCIA, T. M. F. B. Cotidiano escolar, livros didáticos e formação docente. In: FONSECA, S.; GATTI JR., D. (Orgs.). Perspectivas do ensino de História: ensino, cidadania e consciência histórica. Uberlândia: Edufu, 2011, p. 361-371.

HALLEWELL, L. O livro no Brasil: sua história. São Paulo: EDUSP, 2005, p. 237.

HÖFLING, E. M. A trajetória do Programa Nacional do Livro Didático do Ministério da Educação no Brasil. In: FRACALANZA, H.; MEGID NETO, J. (Orgs.). O livro didático de Ciências no Brasil. Campinas: Komedi, 2006.

KRASILCHIK, M. O professor e o currículo das ciências. São Paulo, EPU: EDUSP, 1987.

LEÃO, F. B. F.; MEGID NETO, J. Avaliações oficiais sobe o livro didático de Ciências. In: FRACALANZA, H.; MEGID NETO, J. (Orgs.). O livro didático de Ciências no Brasil. Campinas: Komedi, 2006.

LORENZ, K. M. Ação de instituições estrangeiras e nacionais no desenvolvimento de materiais didáticos de ciências no Brasil: 1960-1980. Revista Educação em Questão, UFRN/ Centro de Ciências Sociais Aplicadas, Natal, RN, v. 31, n. 17, p. 7-23. jan./abr. 2008.

MEGID NETO, J.; FRACALANZA, H. O livro didático de Ciências: problemas e soluções. In: FRACALANZA, H.; MEGID NETO, J. (Orgs.). O livro didático de Ciências no Brasil. Campinas: Komedi, 2006.

MELLO, J. C. D. Os livros didáticos nas políticas curriculares para o Ensino Médio. In: REUNIÃO ANUAL DAANPEd, GT, 12., 2005. Anais... Disponível em <http://www. anped.org.br/reunioes/28/textos/gt12/gt121379int.rtf>. Acesso em 15/10/2011. 
ROMANELLI, O. O. História da Educação no Brasil. Petrópolis: Vozes, 1986.

SILVA, E. F.; GARCIA, T. M. F. B.; GARCIA, N. M. D. E agora, que todos têm livro didático de Física? O ponto de vista dos alunos. In: ENCONTRO DE PESQUISA EM ENSINO DE FÍSICA, 12., 2010. Anais... São Paulo: Sociedade Brasileira de Física, 2010. Disponível em: <http://www.sbf1.sbfisica.org.br/eventos/epef/xii/sys/resumos/ T0188-1.pdf $>$. Acesso em 15/10/2011.

WUO, Wagner. A Física e os livros: uma análise do saber em Física nos livros didáticos adotados para o ensino médio. São Paulo: EDUC/FAPESP, 2000.

Texto recebido em 15 de novembro de 2011.

Texto aprovado em 08 de dezembro de 2011. 